\title{
A Rare Pattern of Median Nerve Branching in the Hand
}

\author{
Saurabh Gupta $\quad$ S. Dinesh Kumar ${ }^{1} \quad$ Devi Prasad Mohapatra ${ }^{1} \quad$ Elan Kumar Subbarayan ${ }^{1}$
}

${ }^{1}$ Department of Plastic Surgery, Jawaharlal Institute of Postgraduate Medical Education and Research, Puducherry, India

Indian J Plast Surg

Sir,

Avoidance of injury to recurrent motor branch (RMN) and palmar cutaneous branch (PCBM) of median nerve is of particular importance during carpal tunnel release and repairing traumatic injuries around the wrist. RMN has been named as the "million dollar nerve" due to compensation awarded in lawsuits after its iatrogenic injury. We have encountered a rare case of RMN branching from the ulnar side of the median nerve and exceptionally distal from the transverse carpal ligament (TCL). This was probably secondary to scar entrapment and traction of nerve along with the growth of hand.

Lanz has classified anatomical variations of median nerve branching pattern of wrist in 1977 into four groups which are further divided into subgroups. ${ }^{2}$ Significant inter study differences are found in the prevalence of Lanz's groups among different populations. Agarwal et al have done cadaveric study in Indian population and reported $50 \%$ deviation from the standard text-book anatomy of the median nerve. ${ }^{3}$ They have reported $42.3 \%$ transligamentous, $36.5 \%$ extraligamentous, and $21.15 \%$ subligamentous pattern of RMN branch. ${ }^{3}$ They have not mentioned about side of branching of RMN.
Address for correspondence Devi Prasad Mohapatra, MCh, Department of Plastic Surgery, Jawaharlal Institute of Postgraduate Medical Education and Research, Puducherry 605006, India (e-mail: devimohapatra1@gmail.com).

We explored a left hand of an 18-year-old girl with an old, zone-IV flexor tendon injury. On median nerve dissection, we found RMN arising $1.5-\mathrm{cm}$ distal to the distal border of TCL. This division was from the ulnar most side of the median nerve. The RMN was arising from the second common digital nerve $(\mathrm{CDN})$ and not from the main trunk of the median nerve. Identification of RMN was confirmed using electric nerve stimulator ( - Figs. 1 and $\mathbf{2}$ ). Ulnar side branching of RMN is rare with pooled prevalence $2.1 \%{ }^{4}$ No study has reported branching of RMN after the division of first and second CDN.

This exceptionally distal and ulnar division of RMN probably was a result of scar traction of nerve due to previous surgery. It does not represent a congenital/developmental anomaly. Patient in this report sustained hand injury in childhood around 12 years before presentation. The RMN might have been trapped in the scar and during the period of the growth, and pulled distally.

This abnormal division of RMN could be easily missed and injured during median nerve exploration. Surgeon should always be cautious about abnormal anatomy of the nerve while exploring a case of old injury. The approach to median

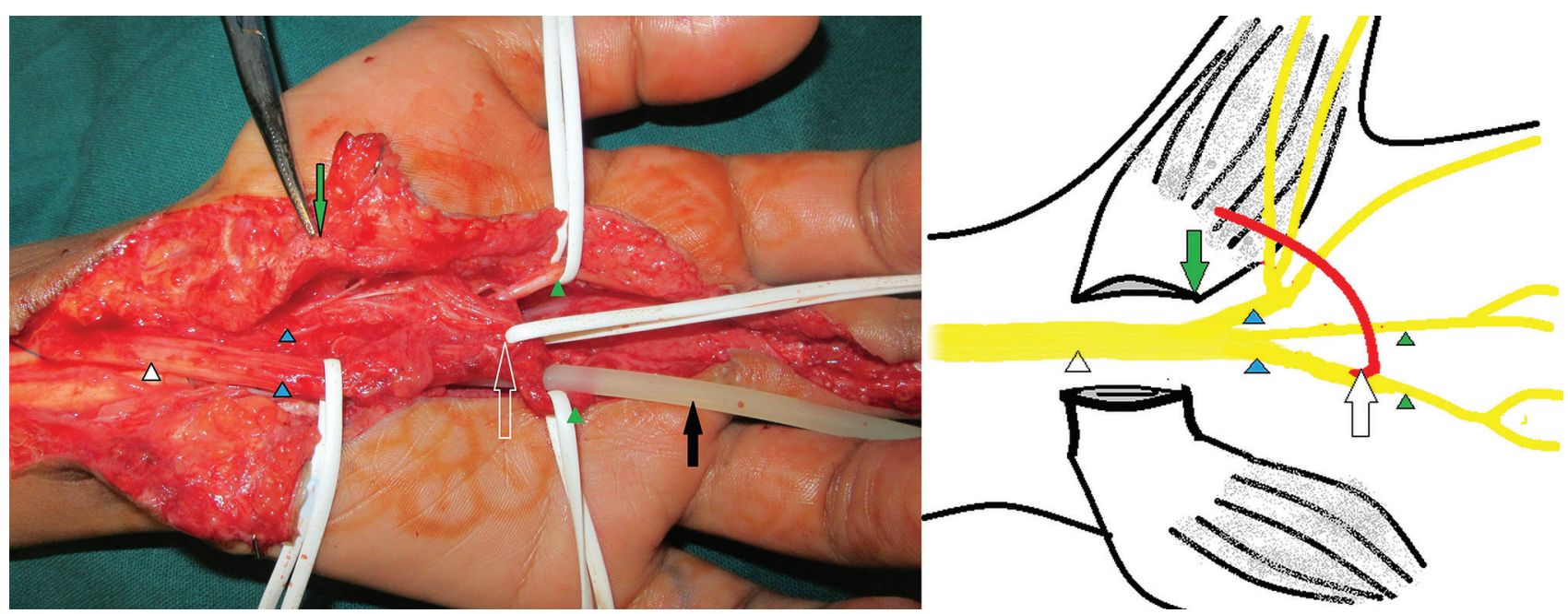

Fig. 1 Distal and ulnar division of recurrent motor branch of median nerve (RMN). It shows median nerve trunk at wrist (white small arrow), medial and lateral branches (blue-small arrow), first and second common digital nerve (CDN; green small arrows), transverse carpal ligament (TCL; green long arrow), RMN arising from second CDN (white-long arrow), and silicone spacer (black arrow).

published online September 23, 2019
DOI https://doi.org/

$10.1055 / \mathrm{s}-0039-1696788$ ISSN 0970-0358.
(C)2019 Association of Plastic Surgeons of India
License terms

(ㄷ) (1) $\ominus$ () 


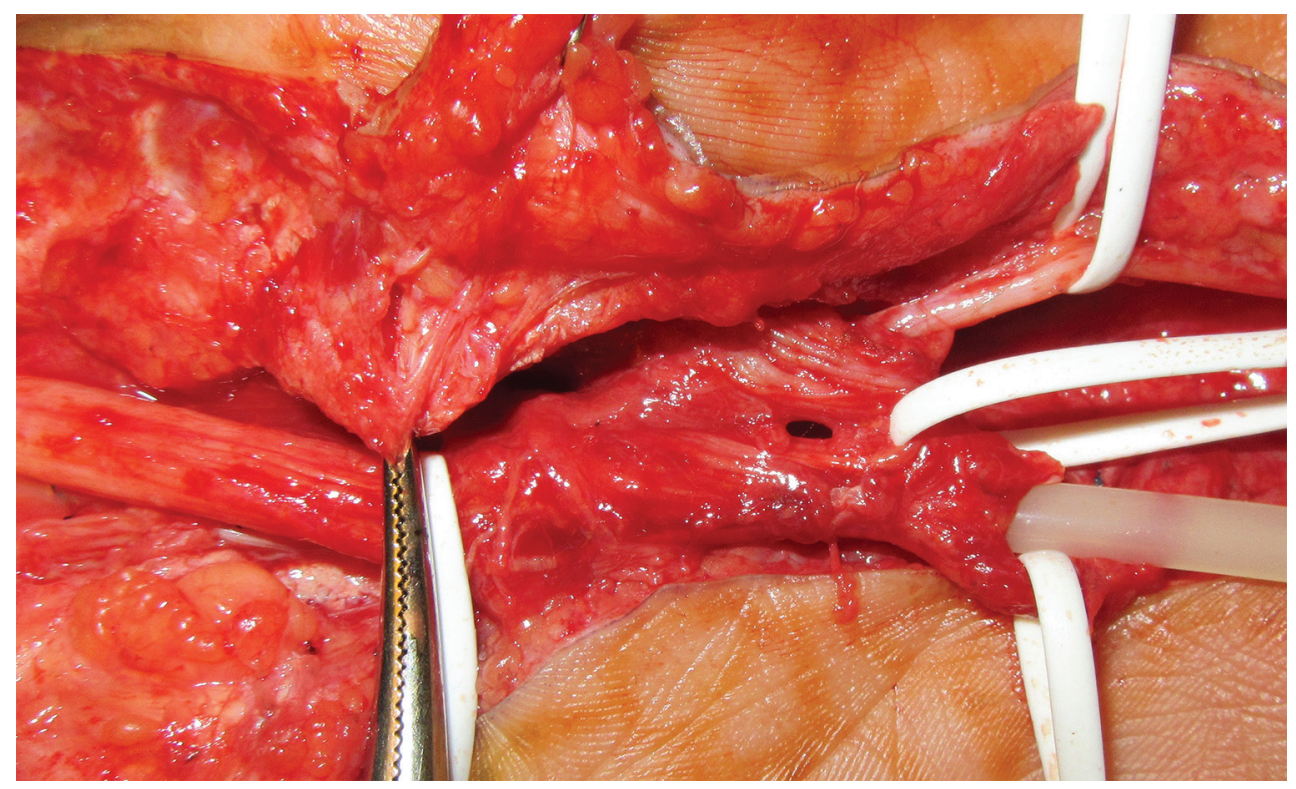

Fig. 2 Close up picture demonstrating the aberrant RMN.

nerve in carpal tunnel should be from its ulnar side. Last but not the least, the ulnar approach also should be cautious, as there are rare instances of ulnar division of RMN.

\section{Conflict of Interest}

None.

\section{References}

1 Krishnan P, Mishra R, Jena M, Das A. Transligamentous thenar branch of the median nerve: the million dollar nerve. Neurol India 2013;61(3):311-312
2 Lanz U. Anatomical variations of the median nerve in the carpal tunnel. J Hand Surg Am 1977;2(1):44-53

3 Agarwal P, Gupta S, Yadav P, Sharma D. Cadaveric study of anatomical variations of the median nerve and persistent median artery at wrist. Indian J Plast Surg 2014;47(1):95-101

4 Henry BM, Zwinczewska $\mathrm{H}$, Roy J, et al. The prevalence of anatomical variations of the median nerve in the Carpal tunnel: a systematic review and meta-analysis. PLoS One 2015;10(8):e0136477 